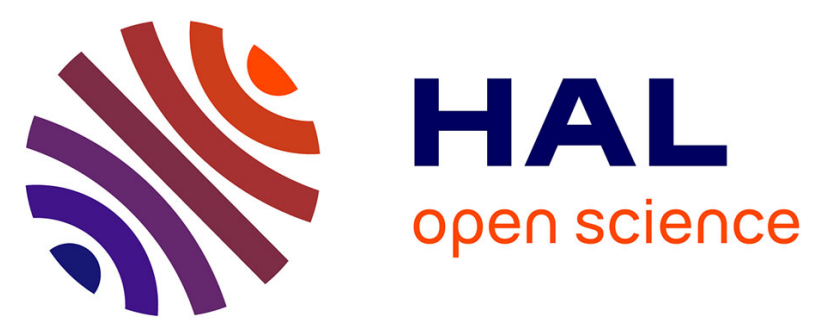

\title{
The influence of the frequency of functional markers on repetitive imitation of syntactic constructions in children with specific language impairment, from their own language productions

\author{
Sandrine Leroy, Christophe Parisse, Christelle Maillart
}

\section{To cite this version:}

Sandrine Leroy, Christophe Parisse, Christelle Maillart. The influence of the frequency of functional markers on repetitive imitation of syntactic constructions in children with specific language impairment, from their own language productions. Clinical Linguistics \& Phonetics, 2013, 27 (6-7), pp.508520. 10.3109/02699206.2013.787546 . halshs-01009178

\section{HAL Id: halshs-01009178 \\ https://shs.hal.science/halshs-01009178}

Submitted on 17 Jun 2014

HAL is a multi-disciplinary open access archive for the deposit and dissemination of scientific research documents, whether they are published or not. The documents may come from teaching and research institutions in France or abroad, or from public or private research centers.
L'archive ouverte pluridisciplinaire HAL, est destinée au dépôt et à la diffusion de documents scientifiques de niveau recherche, publiés ou non, émanant des établissements d'enseignement et de recherche français ou étrangers, des laboratoires publics ou privés. 
Title page

The influence of the frequency of functional markers on repetitive imitation of syntactic constructions in children with SLI, from their own language productions

Sandrine Leroy, Christophe Parisse, \& Christelle Maillart

\section{Corresponding author}

Sandrine Leroy

Ph.D. Student

Department of Psychology: Cognition and Behavior ; University of Liège, Belgium

Rue de l'Aunaie, 30 - Bât. B38 - 4000 Liège - Belgium

E-mail: Sandrine.Leroy@ulg.ac.be

Tel. : +3243665989

Fax : +3243662394

\section{Co-authors}

Christophe Parisse

Reader (Doctor)

Modyco-Inserm, University of Paris Ouest Nanterre la Défense, France

Avenue de la République, 200 - Bât. A, 404B - 92001 Nanterre - France

E-mail: cparisse@u-paris10.fr

Christelle Maillart

Senior Lecturer (Doctor)

Department of Psychology: Cognition and Behavior ; University of Liège, Belgium

Rue de l'Aunaie, 30 - Bât. B38 - 4000 Liège - Belgium

E-mail: Christelle.Maillart@ulg.ac.be 


\begin{abstract}
Several studies provide considerable insight into the role that frequency plays in language development. However, no study has investigated the direct relationship between frequency and grammatical acquisition in children with Specific Language Impairment (SLI). In this study, we focus specifically on the influence of the frequency of functional words on the ability of children with SLI to produce grammatical constructions based on the children's own previous production but containing previously unused functional words. To test our hypothesis, the children were administered an imitative repetition task, tailored to their current level of language development. Results showed that children with SLI performed more poorly than language-matched children with Typical Language Development (TLD). The difference between the two groups was more marked when the previously unused functional words were infrequent rather than frequent. Consequently, it would seem that the token frequency of functional words influences grammatical acquisition in children with SLI. The results and their implications for linguistic theories are discussed.
\end{abstract}

\title{
Keywords
}

Linguistics < language; language acquisition; specific language impairment; functional word frequency; grammatical construction generalisation 


\section{The influence of the frequency of functional markers on repetitive imitation of syntactic constructions in children with SLI, from their own language productions}

\section{Introduction}

Although the role of frequency in language development is attested by all linguistic theories, its influence is interpreted differently from one theory to another. In "Words and Rules" theory (Pinker, 1999), language processing requires two distinct cognitive mechanisms: associative memory and symbol-manipulating rules. Frequency is involved only in the associative memory mechanism which is domain-general and is required for memorizing words and irregular inflections. In contrast with associative memory, symbolmanipulating rules are used for regular inflections, which are productive and involve a ruleprocessing system (Pinker, 1999). This mechanism of symbol-manipulating rules does not require access to the memory store and is not influenced by frequency. Consequently, frequency is important for vocabulary retention but has no role in grammatical development.

In Usage-based theory (Bybee, 1985), frequency influences not only lexical acquisition but also grammatical development. Usage-based theory considers that the mechanisms enabling the creation and retention of grammatical structures are governed by the use of these linguistic forms (Bybee, 1995, 2001; Elman et al., 1996; Langacker, 1987). Children begin their language development with a restricted set of utterances extracted from their language input and acquire language via imitation and intention reading ${ }^{1}$. Subsequently, children become productive by generalizing construction schemas from the entrenched units to never heard items.

\footnotetext{
${ }^{1}$ Intention-reading is a category of general cognitive processes (including joint attention, understanding communicative intentions and cultural learning) by which children attempt to understand the communicative significance of an utterance (Tomasello, 2003).
} 
Because Usage-based theory emphasizes the role of frequency in language development, we decided to investigate the influence of frequency on the language performance of children with specific language impairment. Specific language impairment (SLI) is defined as an impairment of language production, language reception, or both. Language difficulties are present in spite of the absence of any neurological or hearing impairment, or general development delay (Schwartz, 2009). Moreover, children with a diagnosis of Autism Spectrum Disorder are not considered to have specific language impairment. Children with SLI present varied profiles of language deficits (Schwartz, 2009). These deficits can be more marked in some language components than in others. The morphosyntactic domain is considered to be a particularly vulnerable domain in children with SLI (e.g. Hsu \& Bishop, 2011; van der Lely, 2005).

In this study, we investigated the role of frequency of functional words on the performance of children with SLI in an imitative repetition task, where the items to be repeated were created using patterns extracted from the children's own language production. We studied the influence of frequency on the grammatical development of children with SLI. We hypothesized that children with SLI would perform less well than children with typical language development (TLD), particularly when the functional words used to create new patterns to be repeated were infrequent. The items for the repetition task were created from both lexicalized and non-lexicalized patterns, as our second hypothesis was that children with SLI would perform less well for items generated from the lexicalized patterns, because they are more entrenched. The fact that children with SLI could have more difficulties than children with TLD with this task would allow us to attest the role of the frequency of functional words on language development.

\section{Type and token frequencies}


In Usage-based theory, frequency is considered to play a fundamental role in language development. Two types of frequency can be distinguished (Bybee, 2001): token frequency and type frequency. According to Brandt, Verhagen, Lieven and Tomasello (2011, p. 328), token frequency corresponds to "how many times a specific item is used in a specific pattern". It corresponds to the frequency with which a word or a construction is presented in the language input (e.g. he works has a higher token frequency than she quibbles). Token frequency rhymes with entrenchment (Braine \& Brooks, 1995). Entrenchment is defined as the representational strength of a linguistic form in the mind of a speaker. The more frequently children hear and produce linguistic structures and lexical patterns, the more strongly these forms are entrenched in the speaker's grammatical knowledge network. A grammatical structure is acquired and remembered if the minimum threshold required for entrenchment is reached. Bybee (1995) argues that instances with especially high frequency are strongly entrenched and do not lead to generalization because they are lexicalized.

The generalization of schemas depends on type frequency. Type frequency is defined as "how many different items are used in a specific pattern". It corresponds to the number of items which can be used in a specific schema. Bybee (2001, p. 10) gives this example: "English past tense is expressed in several different ways, but the expression with the highest type frequency is the suffix -ed (...) which occurs on thousands of verbs. The pattern found in broke has a much lower type frequency, occurring with only a handful of verbs (...)." Type frequency rhymes with productivity. It promotes the generalization and productivity of construction schemas (Bybee, 1985, 1995). "The productivity of a pattern, expressed in a schema, is largely, though not entirely, determined by its type frequency: the more items encompassed by a schema, the stronger it is, and the more available it is for application to new items" (Bybee, 2001, p. 13). 
Frequency of the activation of the form affects the storage of this information, leading to its final storage as a conventional grammatical unit (Croft \& Cruse, 2004). A form frequently used in the language input can be stored independently of the other forms and can be described as entrenched (Braine \& Brooks, 1995; Langacker, 1987). Consequently, even if a form can be deduced from a more schematic grammatical representation, its entrenchment is possible. While words with a low token frequency are less likely to become entrenched, words with a very high frequency (e.g. the word walked) in language input can be entrenched even if they can be deduced from more general construction schemas (e.g. the construction schema [verb -ed]). Entrenchment also concerns sequences of words. Bannard and Matthews (2008) have shown that children were able to extract and store whole sequences of words directly from the input. When words co-occur frequently together, they are considered as lexicalized units and are hard to dissociate (Bannard \& Matthews, 2008).

\section{Child language development and the frequency effect}

As previously mentioned, frequency influences not only the generalization of construction schemas (Bybee, 2010) but also makes it easier to retain the irregular forms or frequency word sequences (Bannard \& Matthews, 2008; Braine \& Brooks, 1995; Bybee, 1995; Croft \& Cruse, 2004).

In a task involving the repetition of grammatical and ungrammatical sentential complement sentences, Kidd, Lieven and Tomasello (2006) showed that all children performed more poorly with the repetition of sentences containing low frequency complement-taking verbs (e.g. hear) than with the repetition of sentences containing high frequency complement-taking verbs (e.g. think). Moreover, children preferentially corrected ungrammatical sentences containing high frequency complement-taking verbs. The frequency of a complement-taking verb within a complement clause predicted children's ability to repeat 
and correct that construction. The study by Theakston, Lieven, Pine, and Rowland (2004) highlighted the role of frequency in the acquisition of syntax by showing that the best predictor of young children's early use of verbs in multiple syntactic environments was frequency input. The authors investigated the role of semantic generality and the role of the frequency of verb use in the input on the acquisition of individual verbs. Their results showed that although both measures were significantly correlated with the age of acquisition of individual verbs, once the effects of input frequency were removed, semantic generality played a relatively minor role in determining the age of acquisition of verbs. The frequency effect may also influence generalization errors. In an elicited production experiment, Brooks, Tomasello, Dodson, and Lewis (1999) showed that high frequency verbs were less likely to be overgeneralized compared to low frequency verbs which were less familiar. These results support the hypothesis that “(...) children's usage of particular verbs in particular construction types becomes entrenched over time, in the sense that the more familiar children are with a particular verb of fixed transitivity the more reluctant they are to use it in constructions which violate its transitivity status" (Brooks et al., 1999, p. 1333).

Other studies have investigated the role of frequency in the acquisition of word order in an utterance (Abbot-Smith, Lieven, \& Tomasello, 2001; Akhtar, 1999; Matthews, Lieven, Theakston, \& Tomasello, 2005, 2007). In the study by Matthews et al. (2005), children aged $2 ; 9$ were more likely to use an unusual word order with low frequency verbs than with higher frequency verbs. Matthews et al. $(2007, p$. 401) suggested that “(..) children showed more robust preferences for the canonical orders of their language when using lexical items they knew well".

\section{Impact of frequency on the linguistic performance in children with SLI}


Word learning of children with SLI has been shown to be sensitive to input frequency (Gray, 2003; Windfuhr, Faragher, \& Conti-Ramsden, 2002). Frequency affects word production as well as word comprehension. Before understanding a word, children with SLI have to hear this word twice as many times as their peers with TLD (Gray, 2003; Rice, Oetting, Marquis, Bode, \& Pae, 1994). Moreover, children with SLI need twice as many opportunities to practice producing the word compared to their age-matched peers with TLD (Gray, 2003) and their language-matched peers with TLD (Windfuhr et al., 2002), before being able to use a novel word outside its learning context.

Frequency influences lexical learning, as suggested by the SLI critical mass hypothesis (Conti-Ramsden \& Jones, 1997; Windfuhr et al., 2002). According to this hypothesis, children with SLI require a larger number of tokens in order to learn novel lexical items. Moreover, children with SLI require a larger number of types in order to abstract or generalize schemas. Children with SLI will be slower at learning novel lexical items because their acquisition requires more exposure. Children with SLI need a larger critical mass of types and tokens because of their processing limitations (Windfuhr et al., 2002) such as a weak phonological short-term memory (Gathercole \& Baddeley, 1990) or a more general processing capacity limitation (see for example Im-Bolter, Johnson, \& Pascual-Leone, 2006; Marton, Kelmenson, \& Pinkhasova, 2007; Montgomery \& Evans, 2009).

There is a relationship between lexical learning and grammatical development (Windfuhr et al., 2002). The ability to abstract and generalize construction schemas depends notably on a critical mass of information (e.g. verb types). If the critical mass necessary for the generalization of a construction is not reached, children have difficulties in abstracting the schema. Because of this abstraction difficulty, children with SLI use forms as they heard them, without generalization, and are consequently more input-dependent (Conti-Ramsden \& Jones, 1997; Leonard et al., 2002; Riches, Faragher, \& Conti-Ramsden, 2006; Skipp, 
Windfuhr, \& Conti-Ramsden, 2002). For example, Conti-Ramsden and Jones (1997) showed that there is a greater overlap (more than $60 \%$ ) in the use of verbs by the mother-child with SLI dyads than in the use of verbs by the mother-child with TLD dyads.

\section{Objectives of the study}

Previous studies have investigated the role of frequency on the grammatical development in children with TLD. Other studies have investigated the role of frequency in lexical learning in children with SLI. However, no study has investigated the direct relationship between frequency and grammatical development in children with SLI. In this study, we wanted to focus specifically on the influence of the frequency of functional markers on the children's ability to produce grammatical forms involving functional markers not present in previous samples of the children's own production. Previous studies have investigated the role of frequency on language development by using the same experimental task for all the children. However, as the child's language development depends on linguistic input and is influenced by the child's own productions (Tomasello, 2003), we chose to create individualized tasks. Each child was administered a task tailored to her own linguistic developmental level. In other words, we created a task for each child from previous video samplings that consisted in an interaction between the child and one of her parents.

Our hypotheses were tested by a repetition task. There is evidence that when asked to repeat sequences of words, children analyze what they hear and reproduce it as they would a regular utterance (Kidd et al., 2006; Valian \& Aubry, 2005). To better understand the role of frequency on grammatical development, both token and type frequencies were considered. We investigated the role of token frequency by manipulating the frequency of functional words. The role of type frequency was investigated using the children's own lexicalized forms (which in Usage-based theories have a low type frequency) and non-lexicalized forms (which 
in Usage-based theories have a high type frequency). We hypothesized that children with SLI would have more difficulty in repeating lexicalized forms in which a change had been made than when the change was made starting from a non-lexicalised form. Because of their entrenchment as an indivisible whole (Bannard \& Matthews, 2008), a change in a lexicalized form is difficult to accept and produce, particularly for children with SLI who are more inputdependent (Conti-Ramsden \& Jones, 1997; Leonard et al., 2002; Riches et al., 2006; Skipp et al., 2002) and who have less syntactic creativity (Jones \& Conti-Ramsden, 1997; Royle \& Thordardottir, 2008; Stokes \& Fletcher, 2000; Thordardottir \& Weismer, 2002) than children with TLD. Moreover, in agreement with the study by Bannard and Matthews (2008), we predicted that repetition of a changed lexicalized form is even more difficult when the change is infrequent than when the change is frequent, particularly in children with SLI who show sensitivity to token frequency (Gray, 2003, 2004; Windfuhr et al., 2002).

\section{Methodology}

\section{$\underline{\text { Participants }}$}

Fourteen monolingual French-speaking children with SLI (3 girls and 11 boys; aged from $6 ; 6$ to $11 ; 7$ years) were recruited through speech-language therapists, in the Frenchspeaking part of Belgium. Prior to the study, children had been diagnosed with SLI by speech-language therapists and child neurologists. All of the children with SLI had a nonverbal intellectual quotient of 82 or greater. Nonverbal IQ was measured by using Raven's coloured Progressive Matrices (Raven, Raven, \& Court, 1998). Moreover, they had normal hearing, vision, oral and speech motor abilities. Lastly, children with SLI scored more than 1.25 SD below expected normative performance in at least 2 language components. The children's language abilities were assessed by means of a French test, the Evaluation du Langage Oral (ELO: French Language Evaluation - Khomsi, 2001), frequently used by 
French speech-language therapists. This test consists of five subtests. Two subtests are receptive and assess lexical and morphosyntactic reception components. For the two tasks, lexical reception and sentence comprehension, children are instructed to select the picture that corresponds to a word (for lexical reception) or an utterance (for sentence comprehension) spoken by the examiner among four choices. The other three subtests are expressive. The phonological production component is assessed with a word repetition task, and the lexical production component with a picture-naming task. The morphosyntactic production component is assessed with a sentence production task in which children are instructed to finish an utterance presented by the examiner. Eleven children with SLI presented a phonological-syntactic profile, as shown by their poor performance in the "word repetition" and "utterance production" tasks. They attained a score of -1.25 SD or more below the mean at least for these two tasks. The other three children attained a score of $-1.25 \mathrm{SD}$ or more below the mean for the "word repetition" and "lexical reception" task.

Fourteen monolingual French-speaking children with TLD (3 girls and 11 boys aged from 5 to $10 ; 07$ years) were also recruited for this study. Their linguistic performances were controlled and all of them were at or above age-level expectations. Children with TLD were matched to children with SLI on their sentence comprehension abilities. A linguistic-age match was preferred in the present study since, given the language disorders of children with SLI, it seemed evident that their performance in a linguistic task would be poorer than the performance of chronological age-matched children. Several recent studies indicate that children with SLI may not have a deviant developmental trajectory but rather a delayed developmental trajectory (e.g. Hamann et al., 2003; Jakubowicz \& Nash, 2001; Maillart \& Parisse, 2006; Schuele \& Dykes, 2005; Tomblin \& Zhang, 1999). Consequently, it could be expected that children with SLI would have the same performance as younger linguistic agematched children with TLD. Poorer performance in children with SLI compared to their 
linguistic age-matched peers would reflect a real sensitivity of children with SLI to the frequency effect. Moreover, the two groups did not differ in their non-verbal IQ scores. However, both groups were significantly different on all standardized language measures (see Table 1).

- Insert Table 1 about here-

\section{Design}

The children were administered a repetition task, created from their own productions. Tasks were individualized, adjusted to the child's level of linguistic developmental. The creation of the experimental task can be divided in two steps.

First step: recording, transcribing and analyzing a sample of spontaneous language

In order to create individualized tasks, samples of spontaneous language were used. Two tasks were proposed in order to encourage children to speak. In the first task, we proposed a book without text ("Frog, Where are you?", Mayer, 1969) and children had to tell the story. In the second task, children played with one of their parents. About 30 minutes of spontaneous language were recorded and transcribed for each child. These samples were then analyzed and we identified and extracted two types of two-word associations: frequently occurring chunks and infrequent sequences. In the frequently occurring chunks, or lexicalized forms, the two words always occur together (no variability - e.g. le chien (the dog) - le chien (the $\operatorname{dog}$ ) - le chien (the dog)). In the infrequent sequences, or non-lexicalized forms, words were combined with other words (variability - e.g. le chien (the dog) - un chien (a dog) - ce chien (this dog)).

Second step: Creation of the repetition task 
A 60-item repetition task was created for each child. Items were created from the child's own lexicalized and non-lexicalized forms. In these two conditions, one of the two words of the form was modified by either a change using a frequent word or a change using an infrequent word (see Table 2). To decide whether a word creating a change was frequent or not, we used the French database "Lexique3" (New, Brysbaer, Veronis, \& Pallier, 2001). Infrequent change corresponded to an occurrence below 2000 in the "Freqfilm"2 category of the Lexique3 database. Frequent change corresponded to an occurrence above 10000. Lexicalized and non-lexicalized forms were inserted in short sentences. Given that we tested only the ability of the children to repeat the created forms, the created sentences were short in order to avoid memory difficulties. Items were distributed as follows: 10 items created with lexicalized forms with frequent change, 10 items created with non-lexicalized forms with frequent change, 10 items with lexicalized forms with infrequent change, and 10 items with non-lexicalized forms with infrequent change. For the other 20 items, we have used the forms produced by the children during the recording of spontaneous language samples.

\section{- Insert Table 2 about here -}

\section{Procedure}

Participants were tested individually in a single session. The tool used to run the experiment was E-Prime 2 (Psychological Software Tools, 2003). All the sentences were prerecorded by a French-speaking female speaker. To ensure that the children had understood the task and the instructions, they were submitted to a training trial prior to the testing phase. Following the practice trials, the children were presented with the 60 -item repetition task. The task lasted about 30 minutes. The task was inserted inside a story and rewards were given every five items in order to maintain the children's attention during the whole testing phase.

A point was given when the changed form was correctly repeated, i.e. when children correctly repeated lexicalized and non-lexicalized forms which were composed of two words.

\footnotetext{
${ }^{2}$ Freqfilm is defined as frequency of the word in a corpus of subtitles (per million occurrences).
} 
We considered as errors: unintelligible production of the forms (phonetic transcription was impossible); incomplete production of the forms (children produced only one word of the target form); no production of the word; production of another word (children replaced a word by another word). Moreover, a marked phonological deformation was considered as an error when it could create confusion with another form (e.g. e chien - / 2 jjẽ/ - instead of le chien /lə $\mathrm{jje} / ; / \partial /$ is considered as a filler and not as a functional word really known by the child). However, a phonological error which did not hinder comprehension of the form was

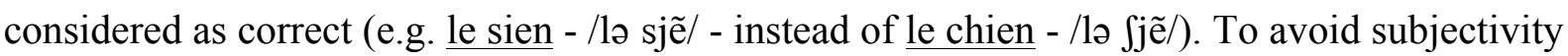
in the data analysis, two persons independently corrected the children's productions. The differences were checked and a unanimous decision reached.

\section{Results}

All the children understood the instructions. No child was excluded from the analyses as all children responded above chance level.

A repeated-measure analysis of variance 2 (Form: lexicalized forms vs. nonlexicalized forms) X 2 (Change: frequent vs. infrequent) with Group (SLI vs. TLD) as the independent variable was performed. Results indicated a significant main effect of Group, $F(1,26)=14.64, p<0.001$, partial $\eta^{2}=0.36$, with overall performances for the children with SLI $(M=7.04 ; S D=3.13)$ being poorer than that of their linguistic age matched peers $(M=$ $9.84 ; \mathrm{SD}=0.42)$. We predicted that repetition of items created with lexicalized collocations would be more difficult because of the entrenchment of the collocation as an indivisible whole. However, statistical analyses revealed no significant main effect of Form, $F(1,26)=$ 0.09, $p=0.76$, partial $\eta^{2}=0.003$. No significant Group X Form interaction was revealed, $F(1,26)=1.73, p=0.2$, partial $\eta^{2}=0.06$. Items created with lexicalized collocations were 
repeated as well as items created with non-lexicalized collocations in the two groups. Analyses revealed a significant main effect of Change, $F(1,26)=8.91, p<0.01$, partial $\eta^{2}=$ 0.25 , with better performance when the change of the function word in the collocation was frequent. Interestingly, there was a significant Group X Change interaction, $F(1,26)=27, p<$ 0.01 , partial $\eta^{2}=0.27$. The difference between children with SLI and children with TLD was more marked when children had to repeat an item in which the change of the function word in the collocation was infrequent $\left(F(1,26)=15.33, p<0.001, \eta^{2}=0.37\right)$ than when the change was frequent $\left(F(1,26)=9.77, p<0.01, \eta^{2}=0.27\right)$. Finally, we predicted that children with SLI would have more difficulty in repeating items created with lexicalized collocations in which the change was infrequent. Statistical analyses revealed no Group X Form X Change interaction, $F(1,26)=1.29, p=0.27$, partial $\eta^{2}=0.04($ see Figure 1$)$.

- Insert Figure 1 about here -

A repeated-measures analysis of variance 2 (Form: lexicalized forms vs. nonlexicalized forms) X 3 (Change: no change vs. frequent change vs. infrequent change) with Group (SLI vs. TLD) as the independent variable revealed a significant Group X Change interaction effect, $F(1,52)=8.16, p<0.001$, partial $\eta^{2}=0.24$. We expected that children with SLI as well as children with TLD would perform near the ceiling for the items with no change because these forms were produced as such during the recording of the spontaneous language samples. However, children with SLI performed less well than children with TLD for the items created with no change, $F(1,26)=14.95, p<0.001, \eta^{2}=0.36$, as well as for items created with frequent change, $F(1,26)=9.77, p<0.01, \eta^{2}=0.27$, and with items created with infrequent change, $F(1,26)=15.33, p<0.001, \eta^{2}=0.37$ (see Figure 2). Moreover, in children with SLI, although there was no significant difference between the repetition of items with no change and the repetition of items with frequent change, $F(1,26)=0.89, p=0.35, \eta^{2}=0.03$, they performed more poorly with items with infrequent change than with items with frequent 
change, $\mathrm{F}(1,26)=18.5, \mathrm{p}<0.001, \eta^{2}=0.41$, and with items with no change, $F(1,26)=20.61$, $p<0.001, \eta^{2}=0.44$ (See Figure 2)

- Insert Figure 2 about here -

\section{Discussion}

While several studies have investigated the relationship between frequency and grammatical development in children with TLD, most studies investigating frequency effects in children with SLI focused on lexical acquisition. In this study, we aimed to study the influence of the frequency of functional markers on the ability of children with SLI (compared to language-matched children with TLD) to produce grammatical forms containing functional markers not used before by the children (the children's use of the functional words was controlled during a previous spontaneous production task).

We modified the functional word of lexicalized and non-lexicalized forms by substituting one functional word by another functional word that was either frequent or infrequent. The frequency of the inserted functional words significantly influenced the performance of children with SLI in this repetition task. Results showed that the performance of children with SLI was poorer than that of their language-matched peers, and the difference between the two groups was more marked when the change in the forms (lexicalized and nonlexicalized forms) involved an infrequent functional word. Moreover, children with SLI performed equally well with the items with frequent change as with items with no change. We deduce that, although children with SLI were able to generalize grammatical forms when the functional words were frequent, they had more difficulty in using infrequent functional words. The children produced an approximation of what they heard: in most cases, the form was preserved (i.e. the association of the two words) but not the functional word. Thus, the token frequency of functional words influenced the performance of children with SLI. 
Our results partially corroborate the observations of previous studies (Conti-Ramsden \& Jones, 1997; Windfuhr et al., 2002), investigating the SLI critical mass hypothesis. This hypothesis postulates that a large number of tokens is necessary for children with SLI to learn a novel lexical item and that a large number of types is necessary to abstract or generalize schemas (Windfuhr et al., 2002). In the present study, children with SLI performed better with items with frequent change than with items with infrequent change. Because the functional word is more frequent, it is more likely to be known and also more likely to be entrenched (Braine \& Brooks, 1995; Bybee, 2001) and, consequently, this form is more easily produced. Concerning the infrequent changes (which are associated with a lower number of tokens), more exposure is required to reach the critical mass necessary for retention of the novel word. While the role of frequency in the use of lexical words (verbs and nouns) has already been established in children with SLI (e.g. Gray, 2003, 2004; Rice et al., 1994; Windfuhr et al., 2002), it seems that the frequency of functional words also influences grammatical acquisition in children with SLI.

According to the SLI critical mass hypothesis (Conti-Ramsden \& Jones, 1997; Windfuhr et al., 2002), a form considered as variable is more easily generalized. In the words of Brandt et al. (2011, p. 328), "patterns that are used with many different items (...) tend to be productive". We decided to test type frequency in our task by manipulating lexicalized and non-lexicalized forms. We surmised that children with SLI would have more difficulties with the repetition of items created with lexicalized forms, which are more strongly entrenched. Given that non-lexicalized forms are more productive, we predicted that children with SLI would accept the changes more easily. However, our results did not corroborate this hypothesis because children with SLI performed equally well for items created from lexicalized forms as with items created from non-lexicalized forms. The variability of the 
form produced during the spontaneous language sample did not seem to help the children with SLI.

\section{Implications for linguistic theories}

The ability of children with SLI to generalize a construction to another construction seems to concern frequent words but not infrequent words. This postulate reinforces Usagebased theories (Bybee, 1985, 1995, 2010) which consider that there is a direct link between generalization and frequency of usage. Our results are compatible with the theory of the Conserving Effect of high token frequency (Bybee, 2010). According to Bybee (2010, p. 75), "each use of a word or construction increases the strength of its exemplar cluster, making that word or phrase more accessible lexically. (...) frequency of use increases the level of resting activation of a stored instance of construction. The greater lexical strength of such an instance makes it more likely to be accessed than a comparable yet more compositional construction".

This approach is opposed to the generativist theory (Pinker, 1994), which posits that grammatical rules can be used irrespective of frequency. In this case, constructions are reproduced by the children only if they have sufficient material to create automatisms. Our results are less compatible with the generativist view, which considers that there is no difference between frequent and infrequent forms since the frequency effect concerns only the retention of lexical items but not grammatical processing. Hence, the grammatical performance of the children should not be dependent on word frequency.

\section{Future perspective}

Given that language input influences the child's language development (Bybee, 1995, 2001; Tomasello, 2003), using the children's own language productions to create our task is relevant. Using conversational language sampling to create the items of our task has a major advantage compared to the use of databases: it makes it possible to obtain information about the child's real language use in a naturalistic context (see also Marinellie, 2004). However, 
the main weakness of the present study is that the spontaneous language samples used are short. The lack of a type frequency effect in our study could be due to this bias. A denser corpus would be necessary to detect what the lexicalized or non-lexicalized forms are exactly. The risk in our study is that, in a short spontaneous language sample, children only produced well known forms because "rare phenomena need denser samples" (Tomasello \& Stahl, 2004, p. 119). Consequently, contrasting lexicalized and non-lexicalized forms is difficult and it is possible that our forms were neither fully lexicalized nor really non-lexicalized. It would be interesting to record children in the same activities several times in order to check whether the chosen forms are indeed lexicalized or not. In fact, with the criteria adopted here, we cannot exclude the possibility that forms considered as lexicalized in our task may prove to be nonlexicalized with a denser corpus. However, there is a high probability that forms which we have considered as non-lexicalized in our task are truly non-lexicalized, given that they were already produced with variability.

It seems unlikely that the difficulties of the children with SLI can be imputed to the nature of the task. While several studies have shown that children with SLI had more difficulties than children with TLD with repetition tasks, these tasks involved non-words (see for example Archibald, 2008; Archibald \& Gathercole, 2006; Estes, Evans, \& Else-Quest, 2007) and sentences (see for example Coady, Evans, \& Kluender, 2010; Stokes, Wong, Fletcher, \& Leonard, 2006) of various levels of complexity. In our study, the forms were short and repetition of the functional words cannot be considered a difficulty because, compared to content words, functional words are often shorter, simpler and unstressed (Hochmann, Endress, \& Mehler, 2010). We therefore tentatively conclude at this stage that the difficulties of the children with SLI may be due to the frequency of functional words. To test this hypothesis, further studies could use a more difficult task. Because children with TLD performed near the ceiling, there was not enough variability in our data. The performance of 
children with TLD was the same in all three conditions (with no change; frequent change; infrequent change). A more complex task such as an elicited production task could be more appropriate.

\section{Acknowledgment}

This work was supported by the Fonds de la Recherche Scientifique - FNRS (Belgium). We thank all the children who participated in the study and their parents for their collaboration. We are grateful to Mélissa Moulin and Marie Vanden Broucke for their assistance in data collection.

\section{Declaration of Interest}

The authors report no conflict of interest. 


\section{References}

Abbot-Smith, K., Lieven, E., \& Tomasello, M. (2001). What preschool children do and do not do with ungrammatical word orders. Cognitive Development, 16(2), 679-692.

Akhtar, N. (1999). Acquiring basic word order: Evidence for data-driven learning of syntactic structure. Journal of Child Language, 26, 339-356.

Archibald, L. M. (2008). The promise of nonword repetition as a clinical tool. Canadian Journal of SpeechLanguage Pathology and Audiology, 32(1), 21-28.

Archibald, L. M., \& Gathercole, S. E. (2006). Nonword repetition: A comparison of tests. Journal of Speech, Language, and Hearing Research, 49(5), 970-983.

Bannard, C., \& Matthews, D. (2008). Stored word sequences in language learning: The effect of familiarity on children's repetition of four-word combinations. Psychological Science, 19(3), 241-248.

Braine, M. D., \& Brooks, P. J. (1995). Verb argument structure and the problem of avoiding an overgeneral grammar. In M. Tomasello \& W. Edward (Eds.), Beyond names for things: Young children's acquisition of verbs (pp. 353-376). Hillsdale, England: Lawrence Erlbaum Associates.

Brandt, S., Verhagen, A., Lieven, E., \& Tomasello, M. (2011). German children's productivity with simple transitive and complement-clause constructions: Testing the effects of frequency and diversity. Cognitive Linguistics, 22(2), 325-357.

Brooks, P. J., Tomasello, M., Dodson, K., \& Lewis, L. B. (1999). Young children's overgeneralizations with fixed transitivity verbs. Child Development, 70(6), 1325-1337.

Bybee, J. (1985). Morphology: A study of the relation between meaning and form. Amsterdam: John Benjamins.

Bybee, J. (1995). Regular morphology and the lexicon. Language and cognitive processes, 10, 425-455.

Bybee, J. (2001). Phonology and language use. Cambridge, UK: Cambridge University Press.

Bybee, J. (2010). Language, usage and cognition. Cambridge, UK: Cambridge University Press.

Coady, J. A., Evans, J. L., \& Kluender, K. R. (2010). The role of phonotactic frequency in sentence repetition by children with specific language impairment. Journal of Speech, Language, and Hearing Research, $53(5), 1401-1416$.

Conti-Ramsden, G., \& Jones, M. (1997). Verb use in specific language impairment. Journal of Speech \& Hearing Research, 40(6), 1298-1313.

Croft, W., \& Cruse, A. (2004). Cognitive Linguistics. Cambridge: Cambridge University Press. 
Elman, J. L., Bates, E. A., Johnson, C. J., Karmiloff-Smith, A., Parisi, D., \& Plunkett, K. (1996). Rethinking innateness: A connectionist perspective on development. Cambridge, MA: The MIT Press.

Estes, K. G., Evans, J. L., \& Else-Quest, N. M. (2007). Differences in the nonword repetition performance of children with and without specific language impairment: A meta-analysis. Journal of Speech, Language, and Hearing Research, 50(1), 177-195.

Gathercole, S. E., \& Baddeley, A. D. (1990). Phonological memory deficits in language disordered children: Is there a causal connection? Journal of Memory and Language, 29(3), 336-360.

Gray, S. (2003). Word-Learning by Preschoolers With Specific Language Impairment: What Predicts Success? Journal of Speech, Language, and Hearing Research, 46(1), 56-67.

Gray, S. (2004). Word Learning by Preschoolers With Specific Language Impairment: Predictors and Poor Learners. Journal of Speech, Language, and Hearing Research, 47(5), 1117-1132.

Hamann, C., Ohayon, S., Dube, S., Frauenfelder, U. H., Rizzi, L., Starke, M., \& Zesiger, P. (2003). Aspects of grammatical development in young French children with SLI. Developmental Science, 6(2), 151-158.

Hochmann, J.-R., Endress, A. D., \& Mehler, J. (2010). Word frequency as a cue for identifying function words in infancy. Cognition, 115(3), 444-457.

Hsu, H. J., \& Bishop, D. V. (2011). Grammatical difficulties in children with specific language impairment: Is learning deficient? Human Development, 53(5), 264-277.

Im-Bolter, N., Johnson, J., \& Pascual-Leone, J. (2006). Processing Limitations in Children With Specific Language Impairment: The Role of Executive Function. Child Development, 77(6), 1822-1841.

Jakubowicz, C., \& Nash, L. (2001). Functional categories and syntactic operations in (ab)normal language acquisition. Brain and Language, 77(3), 321-339.

Jones, M., \& Conti-Ramsden, G. (1997). A comparison of verb use in children with Specific Language Impairment and their younger siblings. Journal of Speech Language and Hearing Research, 40, 12981313.

Khomsi, A. (2001). ELO: évaluation du langage oral. Paris, France: ECPS.

Kidd, E., Lieven, E., \& Tomasello, M. (2006). Examining the role of lexical frequency in the acquisition and processing of sentential complements. Cognitive Development, 21(2), 93-107.

Langacker, R. W. (1987). Foundation of Cognitive Grammar (Vol. 1). Standford, CA: Standford University Press. 
Leonard, L. B., Miller, C. A., Deevy, P., Rauf, L., Gerber, E., \& Charest, M. (2002). Production operations and the use of nonfinite verbs by children with specific language impairment. Journal of Speech, Language, and Hearing Research, 45(4), 744-758.

Maillart, C., \& Parisse, C. (2006). Phonological deficits in French speaking children with SLI. International Journal of Language \& Communication Disorders, 41(3), 253-274.

Marinellie, S. A. (2004). Complex syntax used by school-age children with specific language impairment (SLI) in child-adult conversation. Journal of Communication Disorders, 37(6), 517-533.

Marton, K., Kelmenson, L., \& Pinkhasova, M. (2007). Inhibition control and working memory capacity in children with SLI. Psychologia: An International Journal of Psychology in the Orient, 50(2), 110-121.

Matthews, D., Lieven, E., Theakston, A., \& Tomasello, M. (2005). The role of frequency in the acquisition of English word order. Cognitive Development, 20(1), 121-136.

Matthews, D., Lieven, E., Theakston, A., \& Tomasello, M. (2007). French children's use and correction of weird word orders: A constructivist account. Journal of Child Language, 34(2), 381-409.

Mayer, M. (1969). Frog, Where Are You? New York: Dial Books for Young Readers.

Montgomery, J. W., \& Evans, J. L. (2009). Complex sentence comprehension and working memory in children with specific language impairment. Journal of Speech, Language, and Hearing Research, 52(2), 269288.

New, B., Brysbaer, t., M., Veronis, J., \& Pallier, C. (2001). The use of film subtitles to estimate word frequencies. Applied Psycholinguistics, 28, 661-677.

Pinker, S. (1994). The language instinct. New York, NY: William Morrow \& Co.

Pinker, S. (1999). Words and rules: The ingredients of language. New York, NY: Basic Books.

Raven, J., Raven, J. C., \& Court, J. H. (1998). Manual for Raven's Progressive Matrices and Vocabulary Scales. Section 2: The Coloured Progressive Matrices. Oxford, England: Oxford Psychologists Press.

Rice, M. L., Oetting, J. B., Marquis, J., Bode, J., \& Pae, S. (1994). Frequency of input effects on word comprehension of children with specific language impairment. Journal of Speech \& Hearing Research, $37(1), 106-121$.

Riches, N., Faragher, B., \& Conti-Ramsden, G. (2006). Verb schema use and input dependence in 5-year-old children with specific language impairment (SLI). International Journal of Language \& Communication Disorders, 41(2), 117-135. 
Royle, P., \& Thordardottir, E. T. (2008). Elicitation of the passe compose in French preschoolers with and without specific language impairment. Applied Psycholinguistics, 29(3), 341-365.

Schuele, C., \& Dykes, J. C. (2005). Complex syntax acquisition: A longitudinal case study of a child with specific language impairment. Clinical Linguistics \& Phonetics, 19(4), 295-318.

Schwartz, R. G. (2009). Specific language impairment. In R. G. Schwartz (Ed.), Handbook of child language disorders (pp. 3-43). New York, NY: Psychology Press.

Skipp, A., Windfuhr, K. L., \& Conti-Ramsden, G. (2002). Children's grammatical categories of verb and noun: A comparative look at children with specific language impairment (SLI) and normal language (NL). International Journal of Language \& Communication Disorders, 37(3), 253-271.

Stokes, S. F., \& Fletcher, P. (2000). Lexical diversity and productivity in Cantonese-speaking childrne with specific language impairment. International Journal of Language \& Communication Disorders, 35, $527-541$.

Stokes, S. F., Wong, A. M., Fletcher, P., \& Leonard, L. B. (2006). Nonword repetition and sentence repetition as clinical markers of specific language impairment: The case of Cantonese. Journal of Speech, Language, and Hearing Research, 49(2), 219-236.

Theakston, A. L., Lieven, E. V., Pine, J. M., \& Rowland, C. F. (2004). Semantic generality, input frequency and the acquisition of syntax. Journal of Child Language, 31(1), 61-99.

Thordardottir, E. T., \& Weismer, S. E. (2002). Verb argument structure weakness in specific language impairment in relation to age and utterance length. Clinical Linguistics \& Phonetics, 16(4), 233-250.

Tomasello, M. (2003). Constructing a language: A usage-based theory of language acquisition. Cambridge, MA: Harvard University Press.

Tomasello, M., \& Stahl, D. (2004). Sampling children's spontaneous speech: How much is enough? Journal of Child Language, 31, 101-121.

Tomblin, J., \& Zhang, X. (1999). Language patterns and etiology in children with specific language impairment. In H. Tager-Flusberg (Ed.), Neurodevelopmental disorders (pp. 361-382). Cambridge, MA: The MIT Press.

Valian, V., \& Aubry, S. (2005). When opportunity knocks twice: Two-year-olds' repetition of sentence subjects. Journal of Child Language, 32(3), 617-641.

van der Lely, H. K. (2005). Domain-specific cognitive systems: Insight from Grammatical-SLI. Trends in Cognitive Sciences, 9(2), 53-59. 
Windfuhr, K. L., Faragher, B., \& Conti-Ramsden, G. (2002). Lexical learning skills in young children with specific language impairment. International Journal of Language \& Communication Disorders, 37(4), 415-432. 


\begin{tabular}{|c|c|c|c|c|c|}
\hline \multirow[b]{2}{*}{ Variable } & \multicolumn{3}{|c|}{$\operatorname{SLI}(\mathrm{n}=14)$} & \multicolumn{2}{|r|}{$\operatorname{TLD}(\mathrm{n}=$} \\
\hline & M & SD & Range & M & SD \\
\hline Age (in months) & 107.21 & 22.09 & $75-141$ & 87.71 & 18.64 \\
\hline $\begin{array}{l}\text { Raven's Coloured Progressive } \\
\text { Matrices nonverbal IQ }\end{array}$ & 103.79 & 10.4 & $90-128$ & 106.36 & 10.12 \\
\hline \multicolumn{6}{|l|}{ ELO } \\
\hline Lexical Reception (Z score) & -0.69 & 0.98 & $-2.19-1.12$ & 0.28 & 0.73 \\
\hline Lexical production ( $\mathrm{Z}$ score) & -0.52 & 1.05 & $-2.29-1.43$ & 1.24 & 0.59 \\
\hline Word repetition ( $Z$ score) & -6.17 & 8.72 & $-35--1.4$ & 0.21 & 1.084 \\
\hline Utterance production ( $\mathrm{Z}$ score) & -1.81 & 1.04 & $-3.84-0.1$ & 1.11 & 0.54 \\
\hline Sentence comprehension ( $\mathrm{Z}$ score) & -0.56 & 1.07 & $-2.04-1.65$ & 0.41 & 0.85 \\
\hline Sentence comprehension (Raw score) & 13.29 & 3.43 & $9-18$ & 14.21 & 2.75 \\
\hline
\end{tabular}

Note. IQ $=$ Intelligence Quotient ; ${ }^{*} \mathrm{p}<0.05 ;{ }^{* *} \mathrm{p}<0.01 ; * * * \mathrm{p}<0.001$ 
Table 2.

\begin{tabular}{|c|c|l|l|}
\cline { 2 - 4 } \multicolumn{1}{c|}{ Examples of items } & $\begin{array}{c}\text { Forms with } \\
\text { no change }\end{array}$ & $\begin{array}{c}\text { Forms with } \\
\text { frequent change }\end{array}$ & $\begin{array}{c}\text { Forms with } \\
\text { infrequent change }\end{array}$ \\
\hline Lexicalized forms & The dog eats the meat & A dog eats the meat & Your dog eats the meat \\
\hline Non-lexicalized forms & The jar is empty & A jar is empty & Their jar is empty \\
\hline
\end{tabular}




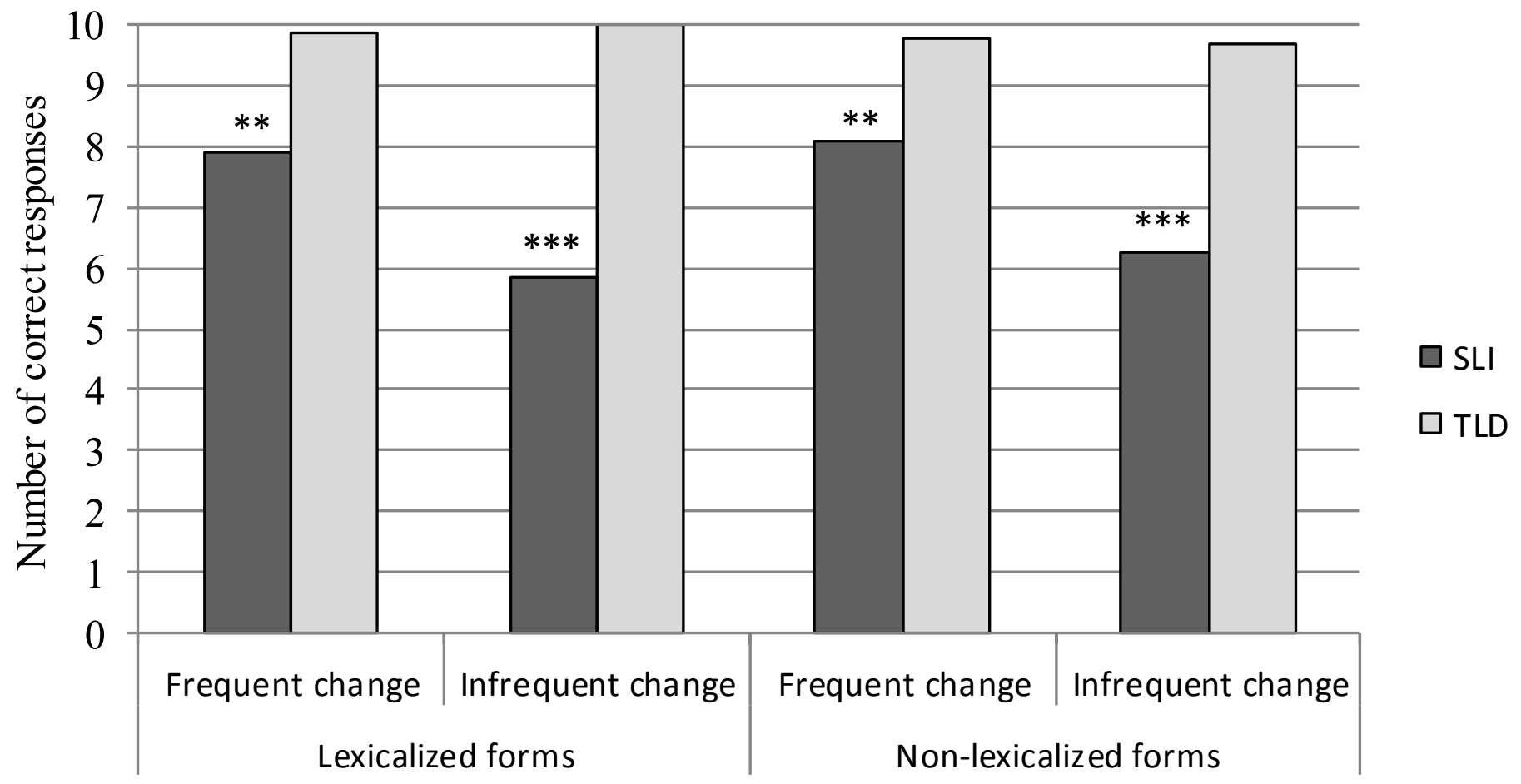

Figure 1. Number of correct responses of the two groups (SLI and TLD), for the items created from lexicalized and non-lexicalized forms, with a frequent and an infrequent change 


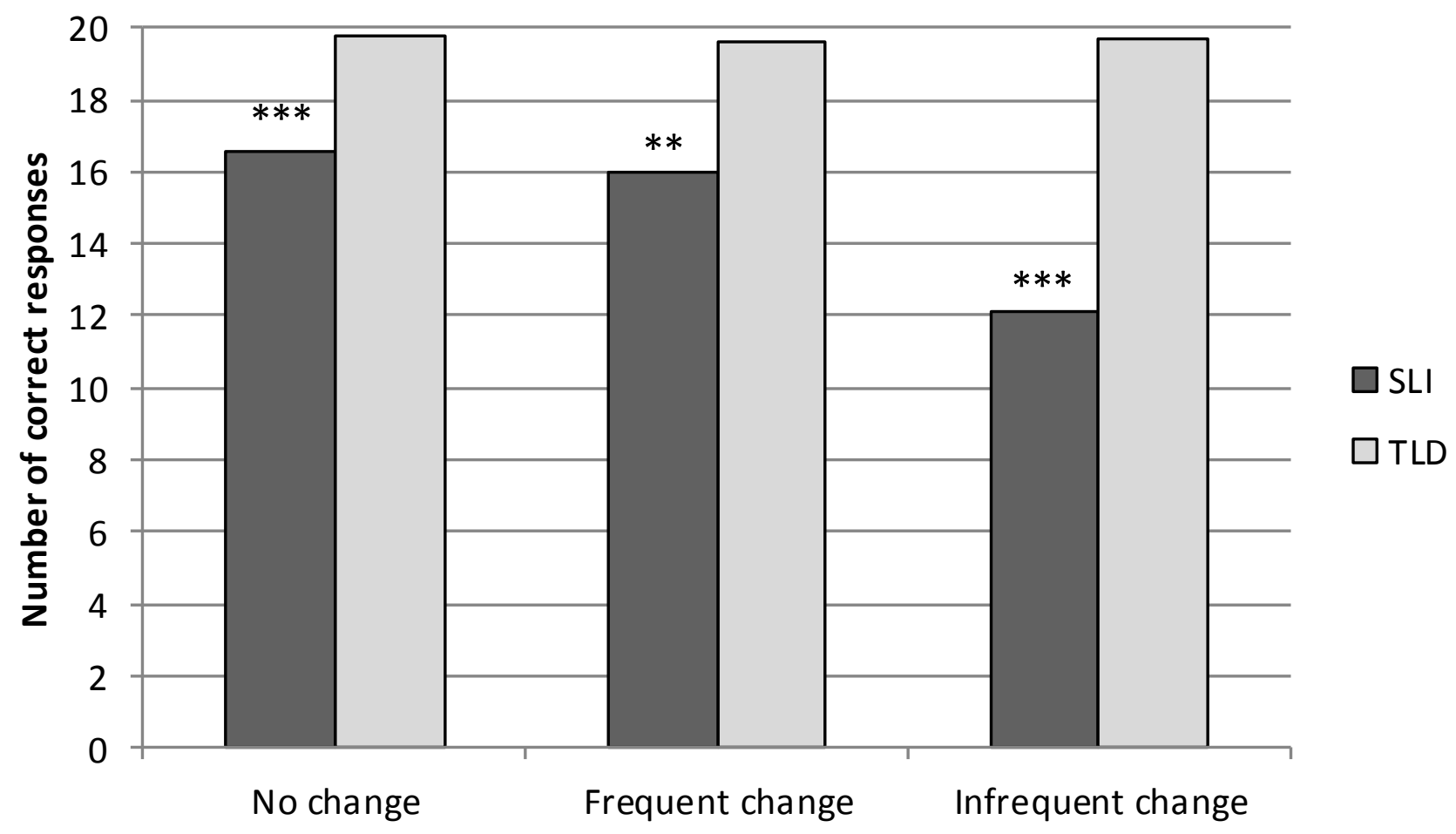

Figure 2. Number of correct responses as a function of the change (no change, frequent change and infrequent change) across the two groups (SLI and TLD) 